\title{
Same or Separate Classrooms: A Twin Bill; The Birth of the Asian Society for Twin Studies; Research Reviews; More Extraordinary Lives of Twins
}

\author{
Nancy L. Segal \\ Department of Psychology, \\ California State University, United States of America
}

This article is dedicated to my dad, Al Segal, who passed away in February 2006.

N ew legislation giving parents a voice in deciding their twins' school placement situation (same or separate classrooms) was passed in Minnesota in spring 2005. Since then, parents in several other states have started petitions and lobbying efforts to persuade their senators and representatives to follow suit. A review and update of these exciting developments is presented, followed by a report from the recently established Asian Society for Twin Studies. Reviews of two new twin studies - bases of political attitudes and age effects on dizygotic twinning - are presented. The uniquely informative lives of several twin pairs are also documented.

\section{Same or Separate Classrooms: A Twin Bill}

New legislation giving Minnesota parents the freedom to decide if their young twins should be placed in same or separate classrooms was described in a recent issue of Twin Research and Human Genetics (Segal, 2005). This legislation, which passed in May 2005, resulted from the lobbying efforts of mothers and fathers, and the receptivity of state senators and representatives. Since then there have been several exciting developments. First, parents in Illinois, North Carolina, Texas, Massachusetts, New York, Georgia, California, North Dakota, Pennsylvania, Connecticut, New Jersey, and Florida have initiated similar movements. Second, a website has been created for disseminating information to individuals interested in learning more about the nature and progress of these activities (www.twinslegislation.com). Third, the media has shown considerable interest in the new legislation, leading to a front-page article in the New York Times (Belafonte, 2006). (The New York Times also published five of the many letters it received from families, both for and against what is taking place.) This story is just starting to unfold as greater numbers of parents are voicing their concerns and taking a stand.

Parental complaints are against school policies requiring separation of young twin children when they enter school. Specifically, twins may suffer unnecessarily from being in an unfamiliar situation without their parent and without their twin - unlike nontwins who separate only from the parent. Some teachers and principals reason that twins will not develop as 'individuals' if they are kept together. However, this belief is not based on research, but on occasional impressions and unsubstantiated assumptions. Furthermore, there is evidence that nontwin children benefit from entering new settings with a friend - they speak more, are more motile and show more positive affect than children who are alone or who are placed with a stranger (although children placed with a stranger adapt with time; Schwarz, 1972; Segal, 2000). However, no-one worries that these children will fail to achieve a sense of self. Clearly, a single policy is inappropriate for all twins, just as it is for all nontwins. Basically, parents of multiples are seeking opportunities for choice regarding the best plan for educating their children. Certainly, some twins will thrive being apart from one another and such twins should be separated - but others might not and would function optimally if they stayed together. I suggest that (for the former) teachers consider assigning twins to different play or study groups within a classroom, allowing them to meet new friends while knowing that their co-twin is close by. Twins do not need to stay together continually to feel secure. When I observed twins' play preferences in unstructured settings, I found that monozygotic (MZ) twins stayed together more often that dizygotic (DZ) twins, but they were not together continually - an occasional glance at their twin was often sufficient for each child to feel comfortable (see Segal, 2000).

\footnotetext{
Address for correspondence: Nancy L. Segal, Department of Psychology, California State University, Fullerton, CA 92834, USA.

E-mail: nsegal@fullerton.edu
} 
Kathy Dolan, mother of identical looking twins, Ryan and Nicholas, is at the center of legislative efforts on behalf of New York families. In her own words, in an e-mail message written to me on February 1, 2006 (edited slightly) she said:

I am trying to get a Twin Legislation Bill sponsored and passed in New York which would allow parents of twins and higher order multiples to have a primary voice in the placement decisions of their children (either separate or together) within the classroom. Last year, Minnesota passed the first ever of its kind 'Twin Legislation Bill', allowing parents a primary voice in the decision-making process and I believe that New York needs to follow suit. Presently, individual principals determine whether or not children will remain together or be separated at school. Decisions are, for the most part, not made on a case-by-case basis. The practice is usually 'across the board', separating all multiples or keeping all multiples together depending on which practice the principal 'feels' is best for all. I, however, believe that ... what is good for one set of multiples is not good for all. Arbitrary separation (or common placement) of twins/higher order multiples, based solely upon their multiplic- ity and past practices of individual principals is, in my opinion, discriminatory and unacceptable ... I am determined to push for legislation on behalf of all twins and higher order multiples and their parents.

I have begun a petition directed to Senator Frank Padavan and have been in contact with Councilman Tony Avello, who will bring this to his Legislative Council as soon as possible. I have also been in regular contact with Senator Frederickson's office in Minnesota who sponsored the bill there.

An on-line petition is available for signatures: http://www.Petition Online.com/ryannick/petition.html

As a point of interest, in 1994 Oklahoma was the first state to adopt a resolution calling for school districts to rethink separation practices for twins, allowing each pair's individual situation to be considered. (This resolution did not become state legislation as happened in Minnesota.) In addition, several well-conducted studies of twins in school have recently been published. They show that separation can be detrimental for some twins (e.g., teacher-rated internalizing problems were more frequent among separated than nonseparated twins at age 7 years; $M Z$ twins showed more negative effects of school separation than DZ twins).
The idea that placement decisions should be made carefully and reviewed periodically was underlined. A sampling of studies and some recent informative reviews are listed below:

Beauchamp, H., \& Brooks, L.J., Jr. (2003). The perceptions, policy and practice of educating twins: A review. Psychology in the Schools, 40, 429-438.

Moskwinski, R. (1999). News, views and comments: School placement of multiples. Twin Research, 2, 239.

Preedy, P. (1999). Meeting the educational needs of pre-school and primary aged twins and higher multiples. In A. C. Sandbank (Ed.), Twin and triplet psychology: A professional guide to working with multiples. London: Routledge.

Tully, L. A., Moffit, T. E., Caspi, A., Taylor, A., Kiernan, H., \& Andreou, P. (2003). What effect does classroom separation have on twins' behavior, progress at school, and reading abilities? Twin Research, 7, 115-124.

van Leeuwen, M., van den Berg, S. M., van Beijsterveldt, T. C. E. M., \& Boosma, D. I. (2005). Effects of twin separation in primary school. Twin Research and Human Genetics, 8, 384-391.

Attention to the new school legislation for twins will continue as more states become active in the process of developing it and getting it passed. Periodic updates will be provided in the News, Views and Comments column of Twin Research and Human Genetics.

\section{The Birth of the Asian Society for Twin Studies}

\begin{abstract}
N ews, Views and Comments welcomes contributions that are of high interest to twin researchers. The following essay documents the creation of the Asian Society for Twin Studies, and the range of projects conducted by its founding members. It was jointly authored by Syuichi Ooki (Ishikawa Prefectural Nursing University), Kenji Kato (The Karolinska Institute) and Yoon-Mi Hur (Seoul National University Hospital, Seoul, South Korea).
\end{abstract}

January 28-29, 2006 was memorable for Asian twin researchers. During these 2 days, a small group of Asian twin researchers gathered in Tokyo, Japan for the first time in the history of Asian twin studies and opened a workshop (January 28, as a special symposium of an Annual Meeting of the Japan Society of Twin Study at Wako University, and January 29, at the Shinjuku Washington Hotel). The Asian Society for Twin Studies (ASTS) was born at the workshop.

Recently, the number of twin registries has been increasing sharply in Asian countries. At the workshop, the ASTS members discussed the current status and future directions of twin studies in Asia. Asian twin cohorts are of special significance in the era of genomic research and offer novel opportunities to understand the role of genes and environments in the development of normal human traits and diseases. Asian twin cohorts also provide valuable opportunities for investigations of the genetic and environmental origins of cultural diversity in humans. At the workshop, the ASTS members agreed to convene workshops on a regular basis to promote strong relationships, active communications, and collaborations among Asian twin researchers for the further development of twin studies in Asia. Table 1 lists the participants 
Table 1

A List of Participants and the Titles of Presentations

\begin{tabular}{|c|c|c|c|}
\hline Country & Name of participants & Affiliations & Titles of presentations \\
\hline \multirow[t]{2}{*}{ China } & \multirow{2}{*}{$\begin{array}{l}\text { Zengchang Pang } \\
\text { and Huaqiang Zhang }\end{array}$} & \multirow{2}{*}{$\begin{array}{l}\text { Qingdao Municipal Centers for } \\
\text { Disease Control and Prevention }\end{array}$} & Twin Registry in Qingdao, China (Pang Zengchang and Huaqiang Zhang) \\
\hline & & & $\begin{array}{l}\text { Analysis on the sex difference of heritability of skeletal age in twins } \\
\text { (Pang Zengchang) }\end{array}$ \\
\hline \multirow[t]{5}{*}{ Japan } & Juko Ando & Keio University & Keio Twin Project: Overview (Juko Ando) \\
\hline & Koichi Nonaka & Wako University & $\begin{array}{l}\text { Tokyo Twin Cohort Project (ToTCoP): Its beginning and related issues } \\
\text { to be considered (Koichi Nonaka, et al.) }\end{array}$ \\
\hline & Noriko Kato & National Institute of Public Health & Using vital statistics of Japan for twin studies (Noriko Kato) \\
\hline & Syuichi Ooki & Ishikawa Prefectural Nursing University & $\begin{array}{l}\text { Twin database of the secondary school attached to the Faculty of } \\
\text { Education of the University of Tokyo (Syuichi Ooki) }\end{array}$ \\
\hline & Kenji Kato & The Karolinska Institute & \\
\hline \multirow[t]{2}{*}{ Singapore } & Kee Seng Chia & National University of Singapore & The Singapore Twin Project (Kee Seng Chia) \\
\hline & & & Beyond twins (Kee Seng Chia) \\
\hline \multirow[t]{2}{*}{ Sri Lanka } & $\begin{array}{l}\text { Athula Sumathipala } \\
\text { and Sisira Siribaddana }\end{array}$ & Sri Lankan Twin Registry & $\begin{array}{l}\text { Establishing a population-based twin register — Sri Lankan } \\
\text { experience (Sisira Siribaddana et al.) }\end{array}$ \\
\hline & & & Starting from scratch in Sri Lanka (Athula Sumathipala) \\
\hline \multirow[t]{2}{*}{ South Korea } & \multirow{2}{*}{$\begin{array}{l}\text { Yoon-Mi Hur } \\
\text { and Kun Woo Kim }\end{array}$} & \multirow[t]{2}{*}{ Seoul National University Hospital } & Seoul Twin Family Study: An expansion (Yoon-Mi Hur et al.) \\
\hline & & & $\begin{array}{l}\text { Are genetic and environmental influences on birth weight similar } \\
\text { between Caucasians and East Asians? A comparison of data from } \\
\text { America, Australia, the Netherlands, Japan, and South Korea (Yoon-Mi } \\
\text { Hur et al.) }\end{array}$ \\
\hline Taiwan & Chaucer C. H. Lin & Tzu Chi University & $\begin{array}{l}\text { Heritability of schizotypy: A study on Taiwanese juvenile twins } \\
\text { (Chaucer C.H. Lin et al.) }\end{array}$ \\
\hline
\end{tabular}

from six Asian countries (China, Japan, Singapore, Sri Lanka, South Korea, and Taiwan), followed by a brief summary of each presentation.

\section{$\overline{\text { China }}$}

Pang and Zhang presented an overview of the Qingdao Twin Registry (QTP). As part of the Chinese National Twin Registry, the QTP was established in 2001 to provide a long-term special population resource for genetic epidemiological studies of etiologically complex diseases and related phenotypes. Currently, approximately 9000 twin pairs of all age groups in Qingdao have registered in the QTP registry. On the basis of the QTP registry data, Pang and Zhang demonstrated significant heritability of skeletal age and gender difference in the heritability of skeletal age.

\section{Japan}

Ando presented an outline of the ongoing Keio Twin Project, a comprehensive behavioral genetic project with approximately 800 pairs of adolescent and young adult twins (starting from 1998), and its major findings. Nonaka et al. presented an outline of the ongoing Tokyo Twin Cohort Project (ToTCoP), which began in November 2004 as a 5-year longitudinal research project on population-based newborn twin cohorts in the Tokyo metropolitan area. Kato presented the usefulness of vital statistics of Japan for twin studies, which are systematically stored on magnetic tape data files by the Ministry of Health, Labor and Welfare. Ooki presented a historically unique twin database of the secondary education school attached to the faculty of education of the University of Tokyo, published in Twin Research, 7 (2004) and Twin Research and Human Genetics (2005).

\section{Singapore}

Chia described the recent increase in twinning rates in Singapore and an outline of the Singapore Twin Project (STP). As a very recently developed project, the STP attempts to recruit all twins who were born and currently reside in Singapore. Biobanks and the medical record data for these twins are being constructed. Chia also discussed the importance of studying the interaction of genes and environments for understanding the etiology of complex diseases.

\section{$\overline{\text { Sri Lanka }}$}

Siribaddana presented an overview of the Sri Lankan twin registry and its current expansion. The Sri Lankan twin registry is a population-based registry that includes approximately 9000 twin pairs of all ages. The major aim of the Sri Lankan registry is to provide a resource for the study of genetics and environmental risk factors in the development of psychiatric diseases. Sumathipala discussed ethical issues for genetic studies and twin research and current activities to promote twin studies in Sri Lanka.

\section{$\overline{\text { South Korea }}$}

Hur and her colleagues from South Korea presented an outline of the ongoing Seoul Twin Family Study (STFS) and its current expansion. The STFS registry was originally developed using twins enrolled in all private and public schools in Seoul, South Korea. Currently, Hur and her colleagues are 
extending the STFS registry to include school-age children in other cities and rural areas in South Korea, and preschoolers throughout South Korea. As an example of international collaboration, Hur et al. also presented an investigation comparing birth weight between Caucasians and East Asians (Hur et al., 2005), showing that the variance in birth weight was significantly larger in Caucasians than in East Asians.

\section{Taiwan}

Lin et al. presented a study of genetic factors relevant to schizotypy, using 366 pairs of Taiwanese juvenile twins and siblings. The Lin et al. study suggested that there is a moderate heritability underlying the development of schizotypy, and that the heritability of schizotypy may differ qualitatively in the two genders, being additive in males and non-additive in females.

\section{Research Reviews}

\section{Twin Study of Political Leanings}

Once again, results from twin studies are challenging common assumptions and providing new challenges to established scholars. Alford et al. (2005) recently reported a provocative twin-based analysis of political attitudes and orientations. They addressed important questions such as: why is a left-right spectrum evident across cultures and across time? Why have studies examining child socialization and political attitudes revealed few conclusive findings?

Participants included several thousand twins from the Virginia Twin Registry who had completed 28 items from the Wilson-Patterson (W-P) Attitude Inventory. All items showed greater resemblance for $\mathrm{MZ}$ than DZ twin pairs - for example, correlations for school prayer were $.66(\mathrm{MZ})$ and $.46(\mathrm{DZ})$; correlations for gay rights were $.60(\mathrm{MZ})$ and .46 (DZ). Heritability ranged from .18 (federal housing) to .41 (school prayer and property tax), with a mean of .32. The nonshared environment made a larger contribution $($ mean $=.53)$ than the shared environment (mean $=.16)$.

Alford et al. (2005) explain their genetic findings with reference to complex gene configurations underlying personality traits, such as openness to experience, that may affect which political attitudes people favor. Genes do not work in isolation, but are expressed within prevailing social conditions. The investigators also suggested that population variation in political attitudes may underlie group viability. This would parallel the idea that trait variability is adaptive for ensuring survival of organisms under changing environmental conditions. This paper will, hopefully, encourage political scholars to consider a genetic perspective in future studies.

\section{Paradox Resolved: Declining Fertility in Older Mothers}

Twins and their families pose numerous scientific problems and paradoxes, one of which has finally found a solution. It has been known for some time that women approaching their mid30 s are at increased risk for conceiving DZ twins (Corney et al., 1979). However, this elevated risk co-occurs with women's age-related decline in fertility. Recently, Dutch investigators have reconciled these opposing tendencies.

Beemsterboer et al. (2006) compared follicular growth and FSH (follicle stimulating hormone (FSH)) concentrations in women between the ages of 24 and 29 years, and 30 and 34 years. The mean age of women with monofollicular growth was 34.6 years and the mean age of women with multifollicular growth was 36.1 years, a difference that was statistically significant. Both multifollicular growth and FSH levels increased with age for women in

\section{Acknowledgments}

The authors gratefully acknowledge the help of Toshimi Ooma with the preparation of this meeting. The workshop was supported by a Grantin-Aid from the Ministry of Education, Culture, Sports, Science and Technology of Japan (No. 17639007, Research members: Syuichi Ooki, Juko Ando, Noriko Kato, Koichi Nonaka). both groups, although FSH levels were higher among women in the multifollicular group. In the younger age group, FSH concentration did not differ between women with mono- or multifollicular growth although only $8 \%$ of these women showed multiple follicles. However, among participants in the older age group, FSH levels were significantly higher for those showing multiple follicles. The investigators reasoned that the age-related increase in multiple follicular development may be linked to rising FSH concentrations induced by negative ovarian feedback. As such, FSH levels may exceed their threshold, leading to multiple ovulation and DZ twins.

The increased risk of DZ twinning with maternal age may also be interpreted in evolutionary perspective. Forbes (1997) proposed that DZ twinning may represent an adaptive exchange, such that the benefits of a successful multiple pregnancy may offset the risks and costs of producing children with genetic defects. (It is well known that older mothers are at elevated risk for conceiving children with Down Syndrome and other genetic disorders and birth anomalies.) In short, the functional explanation for DZ twinning could be a final effort to transmit one's genes into future generations. 


\section{More Extraordinary Lives of Twins}

\section{The Life Not Lived}

Many MZ twins live parallel lives, but sometimes they are given the rare chance to see themselves in a life not lived. This happened to Neeta Jain when her MZ twin sister, Neelu, suffered a severe skiing accident (Jain, 2006). Fortunately, Neelu recovered completely, but some effects of the accident were lasting. 'She stepped off our path', Neeta admitted. In college, Neelu gravitated toward human geography and economics and away from the premedical program her sister followed. After college graduation, Neeta went to medical school, while Neelua enrolled in a business program. Today, Neeta is a doctor, while Neelua runs a yoga company. The physician envies her entrepreneurial sister's more relaxed and varied life style, but knows that she can reclaim elements of it in the future.

\section{The Twins of Rennselaerville}

Claude and Clyde Bryan are a local legend (Parry, 2006). They were born on July 23, 1923 and lived virtually identical lives. They graduated from high school at age 14 years. Then, despite their high intellect and love of learning, they remained together on their family's farm. They loved American history and were famous for their knowledge of Civil War battles, heroes and statistics. The only significant difference between them was that Clyde married - but the twins remained close and in their later years, Claude moved in with his twin and sister-in-law.

The brothers passed away at age 82 years, just 3 months apart. Clyde died first, from complications associated with Alzheimer's disease. Claude died from heart failure, combined with Alzheimer's disease complications. Clyde, sensing that his twin brother depended on him, had hoped that Claude would be the first to go. But it didn't work out that way.

\section{Truly Fraternal Girls}

I have identified several unusual DZ twin pairs whose parents' ethnic back- grounds differ. Twins in one such pair, profiled in Entwined Lives (Segal, 2000), had a white-Filipino father and a black mother. The twins, Lacresha and Jamisha, showed a marked contrast in skin tone and some facial features - Lacresha resembled their father, while her twin resembled their mother. I described another such pair, one with a Hispanic father and Caucasian mother, in a recent issue of Twin Research (Segal, 2003). Like Lacresha and Jamisha, each twin showed a strong physical resemblance to one parent and little resemblance to one other. Recently, a young pair of DZ twin girls has attracted even more attention (Netscape, 2006).

British twins, Remee and Kian Horder, were born to a couple in which both partners were themselves the products of mixed-ethnic (Black-Caucasian) marriages. It is suspected that Kian (who looks Black) inherited genes conducive to dark skin color from both parents. Similarly, it is reasoned that Remee (who looks White) inherited genes conducive to light skin color from both parents. The twins' mother observed that over the first few weeks, Remee's skin became lighter and her eyes stayed blue, while Kian's skin became darker and her eyes turned brown.

\section{'America's Most Identical Twins'}

America's most identical twins were identified on March 12, 2006, on the Discovery Health channel. The final competition included four of the most similar twin pairs, identified from among many others by program producers at the August, 2005 Twins Days Festival, in Twinsburg, Ohio. In order to reach the final four, twins underwent an extensive test battery including comparison of their taste preferences, body movements, facial structure and hand-eye coordination.

The final four, two MZ male twin pairs and two $M Z$ female twin pairs, were flown to Bethesda, Maryland where they underwent a second series of comparative tests. Here, they were separated from one another and

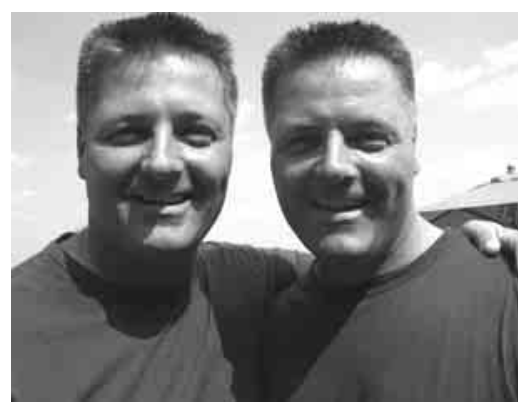

Twin on left is Joey, twin on right is Eddie.

filmed while ordering in a restaurant, shopping for an outfit and meeting a prospective dating partner. The filmed segments were later reviewed by four judges (Drs. Nancy L. Segal and Kerry Jang, and Olympic gymnasts and twins, Paul and Morgan Hamm). The four judges were filmed discussing their observations, as well as related research issues. The winning pair, $\mathrm{MZ}$ males from the east coast, was impressive because they were so similar despite believing they were different.

\section{$\overline{\text { References }}$}

Alford, J. R., Funk, C. L., \& Hibbing, J. R. (2005). Are political orientations genetically transmitted? American Political Science Review, 99, 153-167.

Beemsterboer, S. N., Homburg, R., Gorter, N. A., Schats, R., Hompes, P. G. A., \& Lambalk, C. B. (23 February, 2006). The paradox of declining fertility but increasing twinning rates with advancing maternal age. Human Reproduction [Epub ahead of print] (Advanced Access).

Belafonte, G. (2006, February 2). To keep twins in same class, parents seek legislators' help. New York Times, pp. A1, A21.

Corney, G., Seedburgh, D., Thompson, B., Campbell, D. M., MacGillivray, I., \& Timlin, D. (1979). Maternal height and twinning. American Journal of Human Genetics, 43, 55-59.

Forbes, L. S. (1997). The evolutionary biology of spontaneous abortion in humans. Trends in Ecology and Evolution, 12, 446-450.

Jain, N. (2006, March, April). Split decision. Stanford Magazine, March/April, p. 124. 
Netscape (2006). Who knew twins could look like this? Retrieved March, 2006, from http://channels.netscape. com/ whatsnew/default.jsp?story $=20660313$

Parry, M. (2006, March 13). Twins shared plenty of life with each other. Times Union, pp. B1, 3.
Schwarz, C. (1972). Effects of peer familiarity on the behavior of preschoolers in a novel situation. Journal of Personality and Social Psychology, 24, 276-284.

Segal, N. L. (2000). Entwined lives: Twins and what they tell us about human behavior. New York: Plume.
Segal, N. L. (2003). News, views and comments: Of new interest. Twin Research, 6, 241-247.

Segal, N. L. (2005). News, views and comments: Education issues. Twin Research and Human Genetics, 8, 409-414. 